\title{
Entre salinas, moradias e resort: conflitos de uso e cobertura da terra na Área de Proteção Ambiental de Massambaba, Rio de Janeiro, Brasil
}

\author{
Between salinas, housings and resort: conflicts of use and land cover in \\ Environmental Protection Area of Massambaba, Rio de Janeiro, Brazil
}

Fernanda Lerner Mestre em Engenharia Ambiental pelo Instituto Federal de Educação, Ciência e Tecnologia Fluminense fernandalerner@gmail.com

Carlos André Luz Jeronymo Doutorando no Programa de Pós Graduação em Ambiente da Universidade do Estado do Rio de Janeiro carlosjeronymo@gmail.com

\begin{abstract}
Resumo
A Área de Proteção Ambiental (APA) de Massambaba foi criada com objetivo de conservar fragmentos do ecossistema de restinga, da Região dos Lagos, Rio de Janeiro, Brasil. No entanto, em sua porção no município de Arraial do Cabo, têm se observado ocupações em zonas onde essas atividades são vedadas. O caráter irregular e as sanções sofridas pelos atores locais vêm causando diversos conflitos, principalmente, por ter sido concedida uma licença prévia para um projeto de Eco Resort na mesma localidade. Indaga-se como duas atividades semelhantes de uso dos recursos são tratadas de forma diferenciada pelo poder público. Neste trabalho buscou-se investigar os conflitos de uso e cobertura da terra da APA de Massambaba, em Arraial do Cabo, e especificamente procurou-se alterações nos regulamentos legais relacionados à unidade, para favorecer atores e interesses específicos. Os procedimentos metodológicos envolveram a revisão bibliográfica, pesquisa documental e elaboração de mapeamentos. Conclui-se que houve alterações no Plano de Manejo da APA e seu Zoneamento Ambiental, e essas alterações fragilizaram a gestão da unidade, privilegiaram atores específicos e seus interesses particulares.
\end{abstract}

Palavras-chave: Área de Proteção Ambiental; Massambaba; restinga; conflito; uso e cobertura da terra.

\begin{abstract}
The Environmental Protection Area (EPA) Massambaba was created in order to conserve ecosystem fragments of restinga, of the Lakes Region, Rio de Janeiro, Brazil. However, in its portion in the city of Arraial do Cabo, have been observed occupations in areas where such activities are prohibited. The irregular character and sanctions suffered by local stakeholders have caused many conflicts, especially for having been granted a preliminary license for an Eco Resort project in the same location. It asks as two similar direct use activities of natural resources are treated differently by the government. This work aimed to investigate the conflicts of land use and land cover of Massambaba APA in Arraial do Cabo, and specifically sought changes in the unit related to legal regulations to favor actors and interests. The methodological procedures involved the literature review, document research and development mappings. It was concluded that there were changes in the APA Management Plan and its Environmental Zoning, and these changes weakened the management of the unity, favored specific actors and their interests.
\end{abstract}

Keywords: Environmental Protection Area; Massambaba; restinga; conflict; land use and land cover. 


\section{INTRODUÇÃO}

Área de Proteção Ambiental (APA) é uma categoria de Unidade de Conservação da Natureza (UC) do grupo Uso Sustentável, regida pelo Sistema Nacional de Unidades de Conservação (SNUC). O objetivo desse grupo é compatibilizar a conservação da natureza com a sustentabilidade dos seus recursos naturais (BRASIL, 2000).

As APAs são regidas pelo seu Plano de Manejo e seu Zoneamento Ambiental. O Plano de Manejo é um documento técnico onde constam os objetivos gerais da unidade e se estabelecem as normas que devem presidir o uso e o manejo dos recursos naturais dentro de sua área. Nele também estão inclusos a regulação da implantação das estruturas físicas necessárias à gestão da unidade e seus programas de gestão e planejamento. O Zoneamento Ambiental define zonas homogêneas de restrição de uso e cobertura da terra e recursos naturais da APA (IBAMA, 2001).

As zonas homogêneas constantes no zoneamento devem possuir um padrão espacial com peculiaridades de natureza biótica e abiótica, paisagística, cultural e com características decorrentes dos processos de uso e cobertura da terra, em uma determinada escala e tempo. A delimitação dessas zonas tem por finalidade atribuir controle administrativo por meio de normas restritivas de uso e cobertura da terra e manejo de recursos naturais (IBAMA, 2001).

A Área de Proteção Ambiental na Lagoa de Araruama e Praia de Massambaba, Rio de Janeiro, Brasil foi criada pelo Decreto Estadual $\mathrm{n}^{\circ}$ 9.529-C de dezembro de 1986. Ela abrange os municípios de Saquarema, Araruama e Arraial do Cabo e tem como objetivo resguardar restingas, dunas e lagoas, as espécies de aves migratórias, flora endêmica, além de proteger os testemunhos geológicos e de mudanças climáticas, e sítios arqueológicos (RIO DE JANEIRO, 1986).

O decreto de criação da APA não recomenda a ocupação humana nos limites cartográficos da UC devido às dificuldades para implantação de sistema de esgotamento sanitário e abastecimento de água, além da instabilidade do solo. Mesmo assim as ocupações vêm ocorrendo por meio de loteamentos urbanos regulares e irregulares. Isso se deve ao crescimento urbano desordenado, especulação imobiliária e expansão da atividade turística, especialmente sobre áreas de risco ambiental, Áreas de Proteção Permanente (APP) e de antigas salinas (TERRA, 2012).

Diversas ações judiciais foram protocoladas durante os últimos anos para a retirada de cercas e construções irregulares sobre zonas da APA de Massambaba onde, segundo o zoneamento ambiental, não é permitida a ocupação humana. Por outro lado, há um projeto de um Eco Resort na mesma localidade, com licença prévia concedida pelo órgão executor ambiental estadual, gestor da UC (TERRA, 2012b).

A sociedade questiona o fato do projeto do Eco Resort na APA ter sido aprovado, enquanto construções com a finalidade de moradia não poderem se apropriar desse espaço, em função das 
restrições postas pelo Zoneamento Ambiental. Os atores que apoiam a manutenção das moradias e a instalação de infraestrutura urbana na área apelam para a utilidade pública e o direito de moradia. Para esses atores a construção do Eco Resort beneficiaria apenas interesses particulares.

O objetivo deste trabalho foi discutir os conflitos de uso e cobertura da terra e dos recursos naturais, com ênfase no uso social da terra, especulação imobiliária e a injustiça ambiental na APA de Massambaba. Especificamente procurou-se: levantar os aspectos históricos e sociais da ocupação do município de Arraial do Cabo e da porção da APA localizada no seu território; revisar os aspectos legais relacionados à ocupação de áreas protegidas no Brasil e especificamente na APA de Massambaba; levantar alterações no Plano de Manejo e Zoneamento Ambiental da APA e averiguar se elas beneficiaram o projeto do Eco Resort.

Os procedimentos metodológicos executados neste trabalho envolveram a pesquisa exploratória de gabinete por meio da revisão bibliográfica e pesquisa documental. $\mathrm{O}$ recorte específico da pesquisa buscou, na literatura consultada, construir o cenário da evolução do uso dos recursos naturais e da ocupação da área de estudo e do seu entorno. Também levantou-se as restrições legais de uso e cobertura da terra do município de Arraial do Cabo, da categoria APA e especificamente da UC, além das demais áreas protegidas encontradas na área de estudo.

Também foram elaborados mapeamentos em ambiente SIG, QGIS para:

(a) localizar o empreendimento Eco Resort na área de estudo e no Zoneamento Ambiental da APA de Massambaba. O objetivo desse procedimento foi averiguar a compatibilidade do local a ser instalado o empreendimento e suas atividades, com as categorias de suas respectivas zonas ambientais e as restrições de uso e cobertura da terra associadas a elas;

(b) levantar as áreas protegidas existentes no local escolhido para instalação do empreendimento. Este procedimento buscou levantar quais modalidades de áreas protegidas serão afetadas diretamente pelo empreendimento,e se suas restrições legais estão de acordo ou desacordo com o projeto;

(c) comparar, por meio de sobreposição em tela, o primeiro Plano de Manejo, seu Zoneamento Ambiental e as restrições de uso e cobertura da terra da APA, com sua revisão. O motivo desse procedimento foi verificar se houve mudanças nos limites cartográficos, categorias e restrições das Zonas de Vida Silvestre durante a revisão do Plano de Manejo e seu Zoneamento Ambiental e se essas mudanças favoreceram atores e interesses específicos.

A importância deste trabalho envolve o fato do padrão de ocupação do Brasil ser concentrado historicamente no litoral, levando a uma desestabilização progressiva dos componentes dos ecossistemas de restinga. A restinga na APA de Massambaba, em sua porção Arraial do Cabo, é a mais preservada de toda a UC e a que mais sofre pressão da especulação imobiliária e turismo. 
Por isso, sua conservação é fundamental para manutenção da qualidade ambiental do ecossistema de restinga na APA.

\section{ASPECTOS HISTÓRICOS E SOCIAIS DA OCUPAÇÃO DE ARRAIAL DO CABO}

O município de Arraial do Cabo está localizado no estado do Rio de Janeiro, Brasil, na região conhecida como "Região dos Lagos". Nela localizam-se diversos lagos e lagunas costeiras onde a de Araruama é a maior. Ela possui $220 \mathrm{~km}^{2}$ de área e é considerada a maior laguna hipersalina do mundo (ARRAIAL DO CABO, s.d).

O município de Arraial do Cabo foi criado em 1986, separando-se do Município de Cabo Frio. Ele é conhecido como a "Capital do Mergulho" do estado do Rio de Janeiro, devido a suas águas claras e límpidas e a diversidade marinha beneficiada pelo fenômeno da ressurgência. A prática de mergulho é um dos setores do turismo que mais cresce no município. Com dunas, lagoas, costões, praias, ilhas paradisíacas e sítios arqueológicos, o município oferece variadas opções de lazer (ARRAIAL DO CABO, s.d).

Arraial do Cabo possui 160,286 $\mathrm{km}^{2}$ de área, com uma densidade populacional elevada em relação a outros municípios da região $\left(172,91\right.$ hab./ $\mathrm{km}^{2}$ ). Conforme dados do Instituto Brasileiro de Geografia e Estatística - IBGE - (2014) a população de Arraial do Cabo em 1991 era de 19.866 habitantes, crescendo para 23.877 habitantes em 2000 e 27.715 habitantes em 2010. Vale citar que o município não possui área rural. A Figura 1 demonstra a localização da APA de Massambaba no estado do Rio de Janeiro e na região dos Lagos.

A ocupação histórica da Região dos Lagos está ligada a populações de pescadorescoletores-caçadores, chamados de sambaquieiros. Esses habitavam as áreas em torno dos sambaquis, sítios arqueológicos caracterizados principalmente pelo acúmulo de conchas, cujas construções constituem as ocupações humanas mais antigas presentes na zona litorânea do estado do Rio de Janeiro (GASPAR, 2004). Segundo Gaspar (2004), em Arraial do Cabo, os sítios arqueológicos de origem Itaipu chamados sambaquis estão localizados no interior da APA de Massambaba no entorno do chamado Brejo do Espinho.

Especificamente a ocupação historicamente de Arraial do Cabo está associada à extração de sal nas lagoas costeiras, especialmente na lagoa de Araruama. Beranger (2003) cita nove pontos geográficos onde o sal surgia sem intervenção humana. Desses pontos, três estão na chamada Ponta de Massambaba. As salinas para extração de sal se instalavam nas pontas de terra que entravam mais para o centro da lagoa de Araruama. 


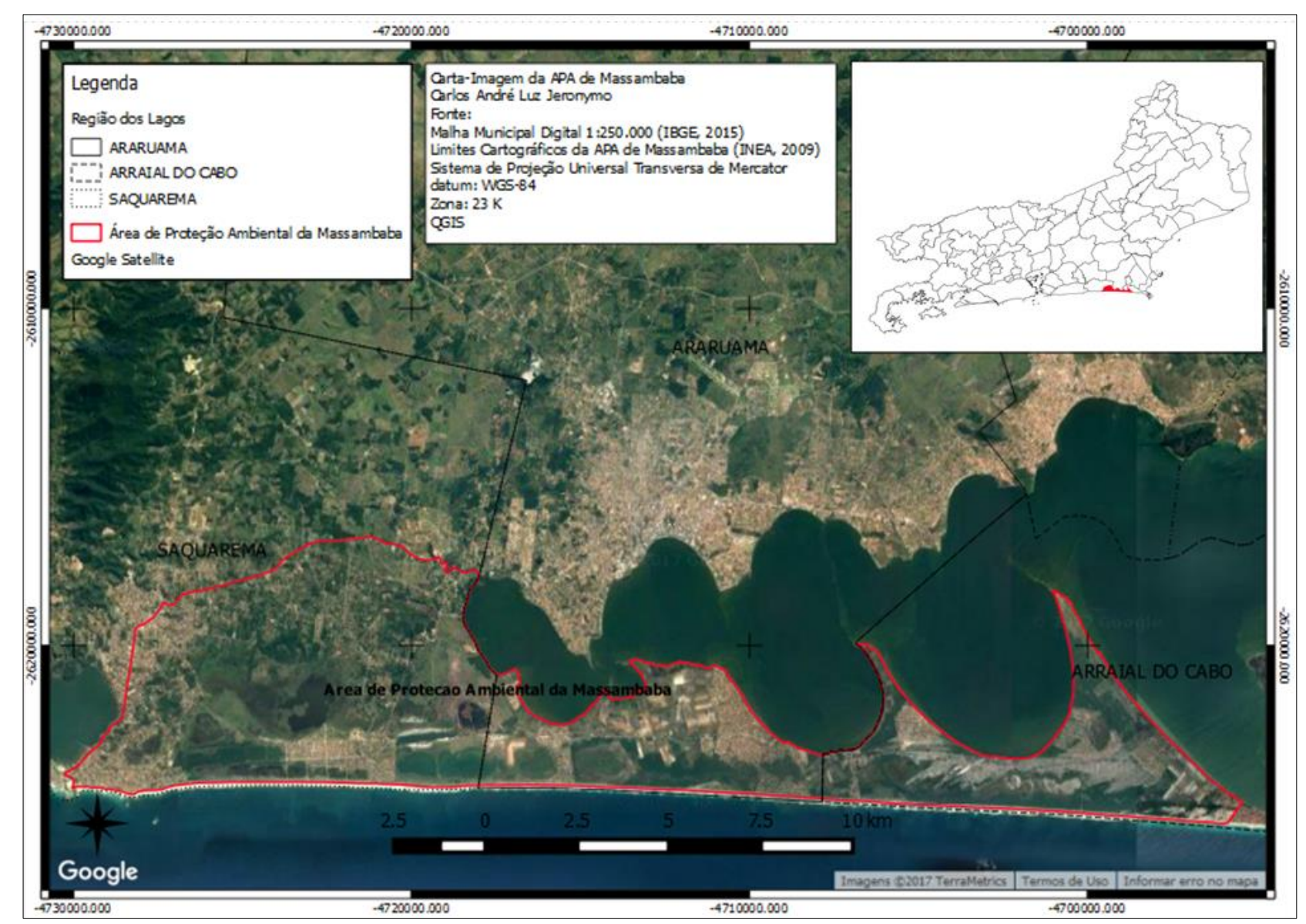

Figura 1: Localização da APA de Massambaba no Estado do Rio de Janeiro.

Fonte: Elaborado pelos autores.

Os primeiros anos do século XX marcaram o incremento das áreas de extração de sal. Nos anos 1950 surgiram refinarias de sal como da Companhia Salinas Perynas e a instalação da Refinaria Nacional do Sal que produziam sal por combustão, em taques de vácuo (PEREIRA, 2009).

A Companhia Nacional de Álcalis (CNA) foi criada em 1943 e inaugurada em 1960 em Arraial do Cabo. A CNA focava na produção de carbonato de sódio e hidróxido de sódio, comercialmente denominados como barrilha e soda cáustica, matérias primas para a indústria de transformação. Antes da chegada da CNA na década de 1960, habitavam Arraial do Cabo os pescadores, os trabalhadores do sal e os catadores de conchas da Lagoa de Araruama (PEREIRA, 2010).

Tanto a exploração do sal como a coleta de conchas eram atividades ligadas à sobrevivência das populações locais, mobilizando muitas pessoas, abrindo novos caminhos para tropeiros e novos canais de comunicação com o interior, á procura de mercados para venda do excedente dos produtos extraídos da lagoa (PEREIRA, 2010).

A construção da CNA trouxe impactos à sociedade de Arraial do Cabo. A empresa inaugurou uma espécie de “divisão social” no lugar, que até 1950 era uma pacata vila de 
pescadores. Têm-se a construção de uma grande indústria exploradora de recursos minerais versus a vida simples dos pescadores, extratores de sal e coletores de conchas. Antes da CNA não havia escolas, médicos, nem rede de telefonia em Arraial do Cabo. "Do dia para a noite" a vila transformara-se no projeto desenvolvimentista brasileiro (PEREIRA, 2010).

Quando da instalação da CNA identificaram-se mudanças na forma de vida dos tradicionais pescadores do lugar não associada diretamente à industrialização, mas a cultura trazida pelos migrantes nordestinos, trabalhadores da CNA e da Companhia Baleeira Thayo. As brincadeiras, orações e encontros tradicionais dos pescadores foram sendo trocadas por hábitos como o cinema e os clubes. A pesca foi sendo substituída por um ganho certo com o emprego na CNA (PEREIRA, 2009).

Com a construção da ponte Presidente Costa e Silva, popularmente conhecida como Ponte Rio-Niterói (1970), houve uma ampliação e dinamização da atividade turística na Região dos Lagos. Consequentemente à dinamização do turismo litorâneo, ocorreu à ampliação da demanda por residências e terrenos para construção de casas de veraneio e rápida expansão dos loteamentos, hotéis e marinas (MELLO et al., 2009).

A CNA foi privatizada no ano de 1992 e no mês de fevereiro de 2004, seu controle passou para a Associação dos Empregados da Álcalis. No ano de 2006 ela gerava cerca de 600 empregos diretos, 200 terceirizados e 1.800 indiretos, sendo responsável por 51,9\% do Produto Interno Bruto (PIB) de Arraial do Cabo. No entanto, em abril de 2004 a produção da fábrica foi interrompida, o que interferiu gravemente na economia do município, visto que a produção da CNA representava 99,9\% do seu PIB industrial (RIBEIRO; GRANATO, s.d).

Embora muitos pescadores tenham trabalhado durante anos na CNA, eles não deixaram a atividade pesqueira por completo. Com os rendimentos na indústria eles adquiriram embarcações novas e maiores. O fechamento da CNA fez com que as populações tradicionais envolvidas com as atividades da indústria voltassem à pesca tradicional, fazendo dessa novamente sua principal fonte de renda e de alimento. Por conseguinte, geraram-se conflitos com pescadores já envolvidos anteriormente na pesca, principalmente pela sobrepesca causada pelo aumento da atividade (MELLO et al., 2009).

O turismo e a pesca, em 2016, são as atividades (excetuando os empregos gerados pela prefeitura) que sustentam a maior parte da população de Arraial do Cabo. A baixa oferta de empregos diretos no município diminui o poder de compra da população e piora a situação econômica da cidade em épocas de baixa temporada (MELLO et al., 2009).

Uma das soluções para a retomada do crescimento do município foi a transformação do Porto do Forno, antes utilizado para o escoamento da produção de sal e dos produtos da CNA, em um porto de assistência a empresas offshore. A perspectiva do porto é de gerar empregos, aumentar 
a arrecadação e o valor dos royalties para o município (MELLO et al., 2009). Entretanto, questionase se ele - assim como o avanço da malha urbana irregular, sobrepesca e turismo - não trará mais problemas sociais, econômicos e ambientais ao município.

\section{3. ÁREAS PROTEGIDAS NO BRASIL E APA DE MASSAMBABA}

$\mathrm{Na}$ legislação federal brasileira estão institucionalizadas diferentes tipos de áreas protegidas, dentre elas: Terras Indígenas, Territórios Quilombolas, Áreas Militares (BRASIL, 1996; 2000; 2003), Reserva Legal (BRASIL, 2012), Áreas de Preservação Permanente (APP) e Unidades de Conservação da Natureza (UC) (BRASIL, 2000). Somente as APP e as APAs, serão trazidas a discussão neste trabalho.

As APPs, segundo o Código Florestal brasileiro, são áreas protegidas, cobertas ou não por vegetação nativa, com a função ambiental de preservar os recursos hídricos, a paisagem, a estabilidade geológica e a biodiversidade, facilitando o fluxo gênico de fauna e flora, protegendo o solo, com intuito de assegurar o bem-estar das populações humanas. No campo específico deste trabalho serão discutidas as APP de entorno dos lagos e lagoas naturais e das restingas, como fixadoras de dunas ou estabilizadoras de mangues, comuns na área de estudo (BRASIL, 2012).

O Código Florestal brasileiro dispõe que o entorno de lagos e lagoas naturais, acima de 20 ha., em zonas rurais, devem possuir uma APP de até 100 metros. No caso daqueles com menos de 20 ha., devem possuir uma APP de 50 metros. Nas zonas urbanas as APPs serão de 30 metros. O município de Arraial do Cabo não possui zona rural então as APPs de lagos e lagoas devem possuir 30 metros (BRASIL, 2012).

Segundo a Resolução do Conselho Nacional do Meio Ambiente (CONAMA) $\mathrm{n}^{\circ} 303$ (BRASIL, 2002), no seu art. $3^{\circ}$, IX, as restingas são APPs em faixa mínima de trezentos metros, medidos a partir da linha de preamar máxima, e em qualquer localização ou extensão, quando recoberta por vegetação com função fixadora de dunas ou estabilizadora de mangues, sendo as dunas também consideradas APPs.

Conforme o Código Florestal (BRASIL, 2012), no seu artigo $8^{\circ}$, a intervenção ou a supressão de vegetação nativa em APP somente ocorrerá nas hipóteses de utilidade pública, de interesse social ou de baixo impacto ambiental. Assim a supressão de vegetação nativa protetora das águas, dunas, e restingas somente poderá ocorrer se autorizada, em caso de utilidade pública.

As UCs brasileiras são geridas por meio do SNUC. São consideradas UCs o espaço territorial e seus recursos ambientais, incluindo as águas jurisdicionais, com características naturais relevantes, com objetivos de conservação. O SNUC divide as UC em dois grupos: de Uso 
Sustentável e de Proteção Integral. Esses dois grupos se subdividem em 12 categorias de manejo distintas (BRASIL, 2000).

Dentre as UC de Uso Sustentável está a categoria da Área de Proteção Ambiental (APA). Pelo SNUC, no seu art. $15^{\circ}$ a APA é uma área em geral extensa, com certo grau de ocupação humana, dotada de atributos abióticos, bióticos, estéticos ou culturais especialmente importantes para a qualidade de vida e o bem-estar das populações humanas e tem como objetivos básicos proteger a diversidade biológica, disciplinar o processo de ocupação e assegurar a sustentabilidade do uso dos recursos naturais (BRASIL, 2012).

A APA é gerida por Conselho Gestor que deve ser formado pelo órgão ambiental executor, poder público, sociedade civil organizada e empresas da região. O conselho faz a gestão e a implementação da UC com base nas orientações do SNUC, na Lei de criação das Estações Ecológicas e das Áreas de Proteção Ambiental (BRASIL, 1981), o Plano de Manejo da unidade e seu Zoneamento Ambiental. Os dois últimos documentos são os principais instrumentos para o controle do ambiente da APA, pois eles contêm a maior parte das restrições de uso e cobertura da terra e dos recursos naturais.

De forma geral, a elaboração dos Planos de Manejo e seus Zoneamentos Ambientais seguem as orientações do SNUC e do Roteiro Metodológico do Instituto Brasileiro do Meio Ambiente e dos Recursos Naturais Renováveis (IBAMA, 2001). Caso esses instrumentos não sejam elaborados, instituídos por meio de regulamento legal e revisados, podem fragilizar a gestão e o controle do ambiente da UC. Além disso, é fundamental que esses documentos representem as realidades e visões de mundo dos atores locais, a fim de evitar conflitos.

A Área de Proteção Ambiental na Lagoa de Araruama e Praia de Massambaba (APA de Massambaba) é uma UC estadual que abrange $76,3 \mathrm{~km}^{2}$. Ela está localizada nos municípios de Saquarema, Araruama e Arraial do Cabo, no estado do Rio de Janeiro. Seu órgão gestor é Instituto Estadual do Ambiente (INEA), que também é o órgão executor ambiental. A APA possui Plano de Manejo, Zoneamento Ambiental e Conselho Gestor instituídos por meio de regulamento legal. O Plano de Manejo e Zoneamento Ambiental já passaram por uma revisão e o Conselho Gestor consultivo possui regimento interno e está em atividade desde 2009 (RIO DE JANEIRO, 2009; INEA 2002; RIO DE JANEIRO, 1986).

A APA de Massambaba foi criada com intuito de resguardar restingas e lagoas em excelente estado de preservação, pois elas abrigam espécies de aves migratórias e espécies vegetais endêmicas. Ainda existe na sua área testemunhos geológico de mudanças climáticas e sítios arqueológicos, fundamentais para o patrimônio histórico e cultural local. A APA foi criada sob a finalidade de manter revestida de vegetação a grande sequência de dunas da região do litoral Fluminense (RIO DE JANEIRO, 1986). 
A região onde se localiza a APA apresenta dois cordões arenosos que separam as lagunas de Jacarepía e Araruama do mar. Ela também é formada por uma série de lagunas menores que estão localizadas entre o reverso do cordão frontal e a frente do cordão mais interiorizado, totalmente isoladas de qualquer aporte fluvial. Na extremidade ocidental, mais afastado do mar em direção ao continente, a topografia deixa de ser plana. Nessa região encontram-se pequenas colinas litorâneas de 30 a 50 m de altura (ARAÚJO et al., 2009).

$\mathrm{Na}$ área da APA de Massambaba foram registradas pelo menos 12 espécies da flora e da fauna endêmicas às restingas fluminenses e mais 14 espécies que ocorrem somente na Mata Atlântica do estado. Também foram apontadas espécies da flora em estado de risco "vulnerável" e cinco em "em perigo", além de quatro novas espécies. Nas lagunas e brejos, o espelho d'água e a vasa lodosa, rica em microrganismos, têm grande variedade e quantidade de microcrustáceos, larvas de insetos, girinos, alevinos e outros pequenos animais (ARAÚJO et al., 2009).

O Brejo do Espinho (Arraial do Cabo) e a Lagoa de Jacarepiá (Araruama), localizados na APA, são essenciais para refúgio, alimentação, reprodução, e descanso de aves migratórias, popularmente chamadas maçaricos, batuíras, peu-peus e gordinhos. Há registros também da ocorrência de colhereiros no Brejo do Espinho, espécie considerada ameaçada de extinção no Estado do Rio de Janeiro (GERÊNCIA DE UNIDADES...,2014). A APA de Massambaba também é importante para a preservação da ave Formigueiro-do-litoral (Formicivora littoralis), espécie endêmica de restinga, tendo a sua área de distribuição restrita principalmente ao longo da restinga de Massambaba (ALVAREZ et al., 2010).

A faixa litorânea da APA de Massambaba também está englobada na Reserva Extrativista Marinha do Brasil (RESEX MAR), criada pelo Decreto Federal $s / n^{\circ}$ de 3 de janeiro de 1997. A RESEX MAR é uma UC de interesse ecológico-social, que visa proteger o sustento da população tradicional (pescadores artesanais), por meio da normatização das diferentes atividades profissionais e amadoras desenvolvidas dentro da RESEX (BRASIL, 1997).

Pela importância histórica, cultural e ambiental da região da Costa do Sol também foi criado em 2011 o Parque Estadual da Costa do Sol, uma UC de Proteção Integral. O parque possui uma área de 9.840,90 ha. e é subdividido em quatro setores, localizados nos municípios de Araruama, Armação de Búzios, Arraial do Cabo, Cabo Frio, Saquarema e São Pedro da Aldeia. O parque tem por objetivo formar um mosaico de 27 Unidades de Conservação que abrangem seis municípios da Região dos Lagos. Um dos setores é parte previamente delimitada da APA de Massambaba (RIO DE JANEIRO, 2011).

O Plano de Manejo da APA de Massambaba e seu Zoneamento Ambiental, aprovados pelo Decreto $\mathrm{n}^{\circ} 41.820$ de 16 de abril de 2009, instituíram a divisão de diferentes zonas homogêneas de interesse ambiental na UC, a fim de disciplinar o uso e cobertura da terra e dos recursos naturais. As 
zonas constituídas são: (i) Zonas de Preservação da Vida Silvestre (ZPVS); (ii) Zona de Conservação da Vida Silvestre (ZCVS); (iii) Zona de Ocupação Controlada (ZOC); (iv) Zona de Influência Ecológica (ZIE) e; (v) Zona de Expansão Urbana e Florestal (ZEUF), sendo que em Arraial do Cabo se encontram somente as seguintes tipologias de zonas: ZPVS, ZCVS e ZOC (RIO DE JANEIRO, 2009).

A ZPVS é aquela destinada à salva guarda da biota nativa através da proteção do habitat de espécies residentes, migratórias, raras, endêmicas, e/ou ameaçadas de extinção, bem como à garantia da perenidade dos recursos hídricos, das paisagens e das belezas cênicas, da biodiversidade e dos sítios arqueológicos. Já a ZCVS é aquela que se caracteriza por admitir uso moderado e autosustentado da biota, apresentando potencial para recuperação ou regeneração futura. A ZOC é aquela que, além de apresentar certo nível de degradação ambiental com menores possibilidades de preservação, fornece condições favoráveis à expansão das áreas urbanas já consolidadas (INEA, 2002).

\subsection{Uso e cobertura da terra da APA de Massambaba (Unidade Arraial do Cabo)}

Até 1960 o município de Arraial do Cabo era uma vila de pescadores e de extratores de sal. Com a chegada da CNA e a construção da ponte Rio-Niterói, a vila de pescadores sofreu um crescimento imobiliário, provocando altas de preços de residências e déficit de ofertas de moradias. Assim, a “"descoberta” da Região dos Lagos e de Arraial do Cabo tornou difícil o acesso a moradia de forma regular, principalmente por parte da população mais vulnerável economicamente.

Nesse sentido, a tendência da expansão urbana de Arraial do Cabo foi tomando a direção oeste do seu centro urbano, em direção aos bairros de Monte Alto, Figueira e Pernambuca, próximos ao limite com o Município de Araruama. Esses bairros estão dentro e no entorno da APA de Massambaba e nessa direção se encontram as ZPVS e ZCVS da área de estudo.

Na década de 1980 e 1990 houve aumento da atuação de grileiros e de loteadores clandestinos, bem como o aumento do número de ocupações irregulares na área da APA de Massambaba e seu entorno. Na obra de Terra (2012) encontram-se relatos da extinta Fundação Estadual de Engenharia do Meio Ambiente (FEEMA), sobre o combate a invasão irregular na área nas décadas de 1990/2000.

As ocupações irregulares ainda vêm ocorrendo nas salineiras desativadas e em desativação, nas áreas protegidas pela legislação ambiental e na região urbanizada de Arraial do Cabo, onde se percebe um processo de favelização. A especulação imobiliária contribui para esses processos, causando também a segregação residencial (TERRA, 2012). 
A segregação residencial tem sido um problema à população de Arraial do Cabo, pois as pessoas tentam buscar em áreas não consolidadas ou sem infraestrutura urbana básica , locais para estabelecer moradia (TERRA, 2012). A autora menciona ainda que haveria no bairro de Monte Alto, em Arraial do Cabo, "perto de 3.000 casas construídas nas dunas locais, caracterizando um processo acelerado de favelização, com muitos moradores vivendo em situação irregular, sem condições de saneamento básico" (TERRA, 2012b, p.6).

O mesmo estudo aponta que nessas áreas a concessionária de energia elétrica não faz a instalação de energia em função da não regularidade das propriedades, e por isso, surgem ligações irregulares que trazem riscos a população. Ainda, as áreas de dunas e restingas, onde cresce o número de ocupações, não são consideradas adequadas para edificações em função das características do solo, o que também traz risco aos residentes (TERRA, 2012).

O crescimento dos núcleos urbanos sobre dunas e praia têm ocasionado danos ao ambiente, visto que as construções e aterros realizados removem a vegetação fixadora de dunas, além de desmontar e remover as próprias dunas. A falta de infraestrutura urbana nessas áreas também resulta em outros danos ao ecossistema, como, por exemplo, a contaminação do lençol freático em razão da falta de saneamento básico e a captação irregular de água em poços artesianos, normalmente contaminados (TERRA, 2012).

Terra (2012b) também evidencia a falta de fiscalização por parte da Prefeitura de Arraial do Cabo e por parte do órgão executor ambiental estadual no que diz respeito às áreas protegidas, principalmente em relação à APA de Massambaba. Segundo a autora, a Prefeitura Municipal de Arraial do Cabo emitiu carnês de Imposto Predial Territorial Urbano (IPTU) para as residências localizadas em áreas de APP no entorno da APA de Massambaba, ou seja, estimulou a ocupação em áreas consideradas protegidas.

Segundo Terra (2012), existe hoje "duas Monte Alto" em Arraial do Cabo: de um lado, uma relativamente urbanizada onde vem sendo implementada infraestrutura e equipamentos urbanos, outra, mais próxima à praia se desenvolvendo sobre APP e locais de risco ambiental. A segunda Monte Alto não é objeto de melhorias urbanas já que, mediante a decisão do poder público, a população ali residente deve ser removida. Conforme a autora, essas áreas já são alvos de constantes ações de despejo por parte do poder público e as pessoas retiradas deveriam ser reassentadas no distrito da Pernambuca, área contínua ao Bairro da Pernambuca. Entretanto, os despejados normalmente se recusam a ir para esse distrito (TERRA, 2012).

O distrito da Pernambuca é uma antiga salineira desativada, por isso Terra (2012b) critica a escolha da localidade não só por ser mais distante do centro de Arraial do Cabo, $31 \mathrm{~km}$ da sede (enquanto que a distância de Monte Alto ao centro é de $15 \mathrm{~km}$ ), mas também porque Pernambuca não possui infraestrutura básica de saneamento, transporte, comércio e saúde. 
A Figura 2 é um mosaico de imagens com algumas características da ocupação no entorno da APA de Massambaba e as características dos lotes vendidos na área.

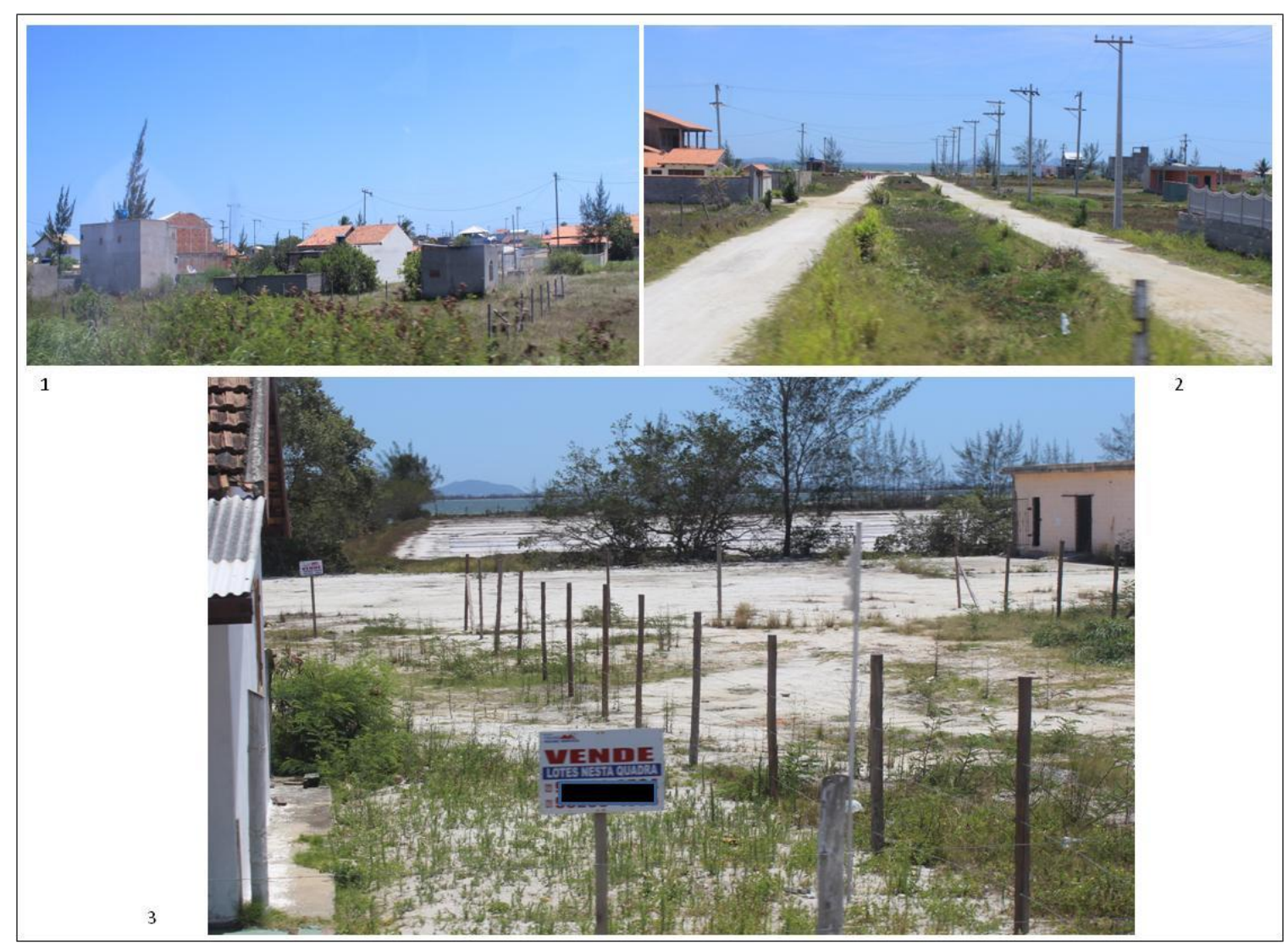

Figura 2: Características da ocupação no entorno e na APA de Massamababa. Destaca-se ao fundo das imagens 2 e 3 a Lagoa de Araruama.

Fonte: Imagens dos autores em dezembro de 2014.

\subsection{Regulamentos legais e o controle do uso e da cobertura da APA de Massambaba}

Segundo o art. $6^{\circ}$ do Plano de Manejo da APA de Massambaba não é permitido o parcelamento do solo na APA: terrenos cujas condições geológicas ou geotécnicas não aconselhem a edificação; ZPVS; ZCVS; cordões de restingas com ou sem vegetação fixadora, alagadiços e brejos, dunas (com ou sem sua vegetação fixadora), manguezais, esporões, praias, áreas estuarinas, nas faixas marginais das lagoas (RIO DE JANEIRO, 2009). Com base nesse artigo do Plano de Manejo pode-se inferir que boa parte das ocupações instaladas na APA de Massambaba e seu entorno, principalmente em Monte Alto, são irregulares.

Ainda pelo Plano de Manejo entende-se que as áreas sujeitas a parcelamento no interior da APA manterão uma faixa de afastamento, nunca inferior a 15 (quinze) metros, não edificável, daquelas denominadas APPs. Dessa maneira, além da área delimitada como APP, existirão mais 15 metros não edificáveis. As construções dentro da APA somente serão permitidas mediante comprovação da implementação de rede e equipamento para abastecimento de água potável, rede de 
escoamento de águas pluviais, rede coletora de esgoto e sistema de coleta de resíduos sólidos (RIO DE JANEIRO, 2009).

Entretanto, não é esse o quadro observado na APA por meio de observação em campo. As ocupações em seus limites cartográficos e no seu entorno, além de não respeitarem a faixa de afastamento no entorno das áreas de APP definida pelo Plano de Manejo, utilizam essas áreas e as APPs para estabelecer suas construções. Como já foi mencionando, essas áreas poderiam ser ocupadas com algumas restrições, caso apresentassem infraestrutura urbana e a questão da utilidade pública.

Outro ponto dessa discussão envolve o fato do Plano Diretor de Arraial do Cabo (ARRAIAL DO CABO, 2006), definir, para fins de ordenação do território municipal, diversas áreas como impróprias para a urbanização. Dentre elas as: (i) Unidades de Conservação da NAtureza, estabelecidas pela legislação federal e estadual e pela Lei Orgânica do Município de Arraial do Cabo; (ii) unidades que venham a ser posteriormente reconhecidas como áreas de preservação, ou recuperação em decorrência de suas características naturais e de seu inequívoco interesse ecológico, paisagístico, cultural e arqueológico; (iii) áreas de risco que se configuram em terrenos frágeis e impróprios para ocupação, especialmente as seguintes: a) Morro do Forno; b) Morro do Miranda; c) Brejo do Espinho; d) Lagoa Salgada; e) Brejo Jardim; (ARRAIAL DO CABO, 2006; 2007).

O Plano Diretor de Arraial do Cabo, no seu artigo ${ }^{\circ} 16$ e $n^{\circ} 18$ também mostra que as dunas de Arraial do Cabo são tombadas pelo Instituto Estadual de Patrimônio Cultural (INEPAC) e são consideradas APP devido à presença de Sítios Arqueológicos (sambaquis). Por essa razão, as áreas das dunas foram consideradas por esse documento como não edificantes. Então, segundo o Plano Diretor, conclui-se que as ocupações e as construções sobre as áreas de restinga e de dunas em Arraial do Cabo, consequentemente na porção da APA de Massambaba no município, são irregulares (ARRAIAL DO CABO, 2006).

Anteriormente vimos que parte da APA da Massambaba engloba o Parque da Costa do Sol. Por isso procurou-se observar seus regulamentos legais relacionados a uso e cobertura da terra e a discussão encaminhada neste trabalho.

No artigo $3^{\circ}$ do decreto de criação do Parque Costa do Sol escreve-se que são vedados empreendimentos, obras e quaisquer atividades que afetem sua substância ou destinação. Ora, parque é uma UC do grupo Integral e tem por objetivo preservar a natureza, sendo admitido apenas o uso indireto dos seus recursos naturais, abrindo exceção apenas nos casos previstos na lei (RIO DE JANEIRO, 2011).

Os parques são criados para preservação de ecossistemas naturais de grande relevância ecológica e beleza cênica. Eles devem possibilitar a realização de pesquisas científicas, o 
desenvolvimento de atividades de educação e interpretação ambiental, recreação em contato com a natureza e turismo ecológico. Portanto, o uso dos recursos naturais de um parque deve ser feito apenas de forma indireta, sendo que áreas delimitadas como pertencentes ao parque devem ser desapropriadas para fins de preservação (BRASIL, 2000).

O Parque Estadual da Costa do Sol ainda não possui Plano de Manejo. Segundo informações na página institucional do INEA, o mesmo está sendo elaborado por equipe técnica já contratada (GERÊNCIA DE UNIDADES...,2014). Dessa forma, enquanto não houver um Plano de Manejo instituído todas as atividades e obras devem ser restringidas àquelas que visem à garantia da manutenção dos recursos naturais da UC (BRASIL, 2000).

Ao analisar o memorial descritivo do decreto de criação do Parque Estadual da Costa do Sol (RIO DE JANEIRO, 2011) notou-se que as ZCVS e ZPVS da APA de Massambaba em Arraial do Cabo fazem parte do parque. Dessa forma, é vedado o uso direto dessas áreas, ou seja, as propriedades particulares nessas zonas devem ser desapropriadas, pois em um mosaico de Unidades de Conservação o uso mais restritivo prevalece (BRASIL, 2000).

Assim sendo, conforme os regulamentos legais que incidem sobre a APA de Massambaba, verifica-se que existe uma série de restrições para o uso e cobertura da terra em sua área e do uso de seus recursos naturais. No entanto, a APA em sua porção de Arraial do Cabo vem sendo ocupada por diferentes tipologias de edificações, além de possuir um projeto de Eco Resort já com licença prévia emitida pelo órgão executor ambiental estadual competente.

\section{O CASO DO ECO RESORT MASSAMBABA}

Além de toda a ocupação urbana desordenada na APA de Massambaba e seu entorno, em janeiro de 2011 o ECORESORT Empreendimentos de Ecoturismo S.A. deu entrada junto ao INEA o pedido de Licença Prévia para a construção de um Eco Resort na APA de Massambaba.

Pelo EIA/RIMA esse empreendimento deverá se localizar numa área junto ao Brejo do Espinho, interior da APA de Massambaba, Arraial do Cabo, numa ZCVS. O empreendimento tem por intuito desenvolver atividades na área de hotelaria, ecoturismo e pesquisa científica. A Figura 3 ilustra a localização do Eco Resort. Ela foi elaborada com base no EIA/RIMA do empreendimento (INEA, 2012).

O Eco Resort tem expectativa de gerar 454 empregos logo após a entrada em operação, dos quais 399 poderiam ser ocupadas pela população no entorno da Área de Influência Direta. No EIA/RIMA a empresa apresenta alguns impactos socioeconômicos, caso a instalação do Eco Resort se consolide como: a valorização dos imóveis do entorno do empreendimento, transtornos à população, aumento do tráfego, atração de população, geração de empregos, aumento da massa 
salarial, aumento temporário da arrecadação municipal e interferência nas atividades de pesca (INEA, 2012).

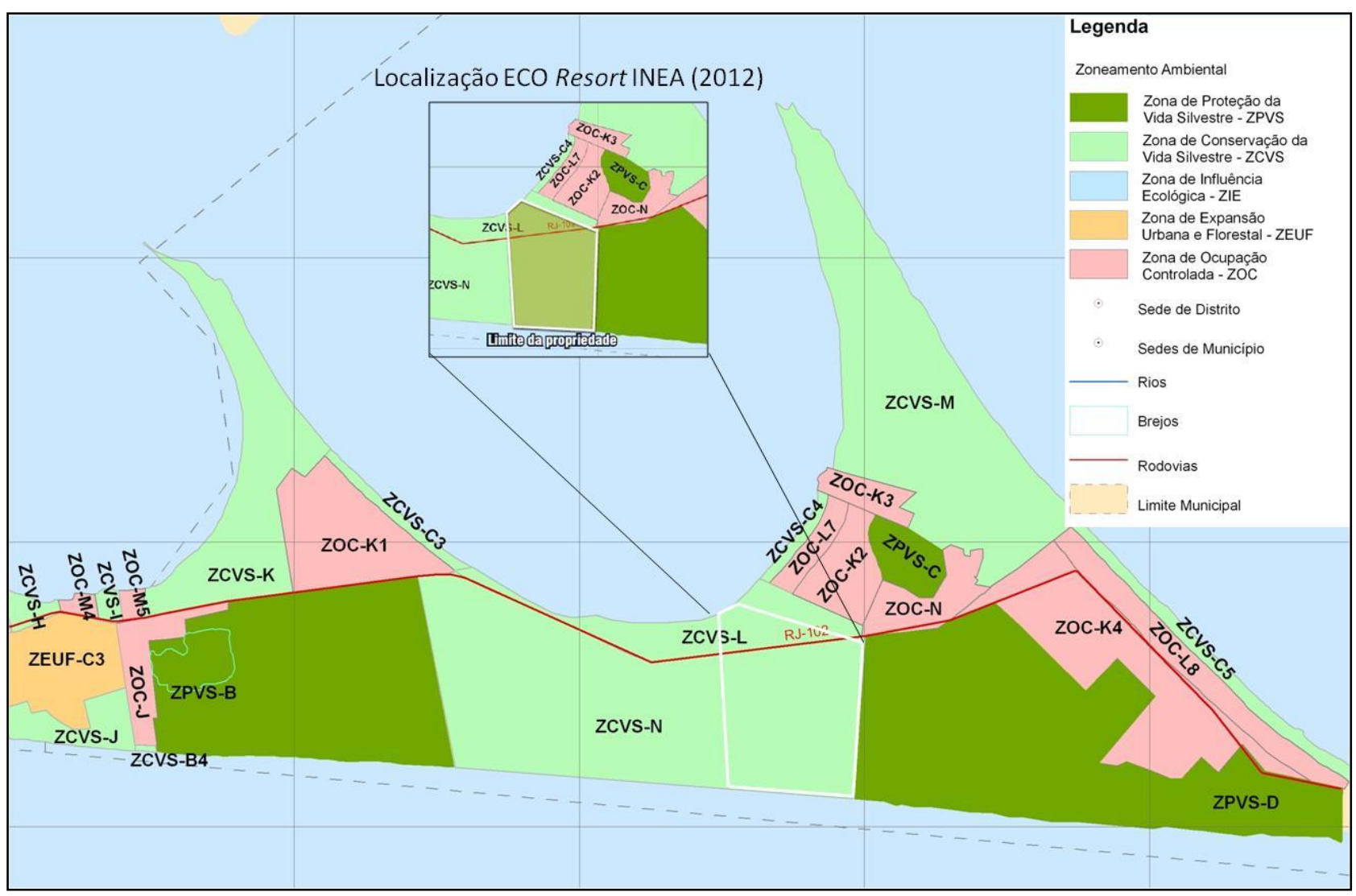

Figura 3- Ilustração da Área da APA de Massambaba em Arraial do Cabo retirada do Plano de Manejo de 2009 e sobreposição da localização do Eco Resort retirada do seu EIA/ RIMA.

Fonte: INEA (2012); RIO DE JANEIRO (2009), adaptado pelos autores em 2015.

Além disso, cita-se o receio à possibilidade do crescimento de tensões em meio às comunidades da Área de Influência Direta do Empreendimento e o crescimento de expectativas negativas em relação ao empreendimento. Esse fato tende a ser intensificado pela experiência pretérita da população na ocorrência de ocupações irregulares e não planejadas, bem como pela insegurança dos atores locais, por não possuírem registro de seus imóveis (INEA, 2012).

O empreendimento propõe a construção de um hotel de 440 quartos na área de ZCVS-L da APA (FIGURA 3), 60 bangalôs localizados na beira do mar onde predominam hoje dunas com vegetação de restinga, centro de estudos e pesquisas ambientais na ZCVS-N e espaço de lazer na beira da Lagoa de Araruama na ZCVS-L. Segundo o EIA/RIMA, as construções do Eco Resort ocuparão áreas nas quais a vegetação já foi alterada ou degradada. Juntos, o Hotel da Lagoa, sua Área de Lazer, o Hotel da Reserva, o Centro de Pesquisas Ambientais, as vias e estacionamento ocuparão menos de 5\% da área total da propriedade, sendo que grande parte do terreno deve ser doado ao Parque Estadual da Costa do Sol (INEA, 2012). 
Ao observar a Figura 3, especialmente à área no entorno e de instalação do empreendimento (ZCVS-L e da ZCVS-N), nota-se que ela está cercada por duas ZPVS (ZPVS-D e ZPVS-B). Nesse sentido, estranhou-se o fato de duas ZPVS estarem separadas por uma ZCVS, pois dificilmente áreas tão próximas e com características ecológicas tão similares possuiriam uma biota e estado de qualidade ambiental diferentes.

Como vimos a ZPVS é aquela destinada à salva guarda da biota nativa por meio da proteção do habitat de espécies residentes, migratórias, raras, endêmicas, e/ou ameaçadas de extinção, bem como à garantia da perenidade dos recursos hídricos, das paisagens e das belezas cênicas, da biodiversidade e dos sítios arqueológicos. Já uma ZCVS é aquela que se caracteriza por admitir uso moderado e auto-sustentado da biota, apresentando potencial para recuperação ou regeneração futura (BRASIL, 1988). Portanto, pela descrição, conclui-se que a ZPVS é mais restritiva no seu uso que a ZCVS.

Mediante o estranhamento de tal fato, além do conhecimento empírico da área, conduziuse investigação para responder o motivo de existir uma ZCVS em meio a duas ZPVS. Analisou-se assim a versão anterior (datada de 2002) do Plano de Manejo e do Zoneamento Ambiental da APA de Massambaba vigente (datada de 2009).

Ao sobrepor em ambiente SIG à área da APA de Massambaba e suas respectivas zonas do ano de 2002 e do ano de 2009, no município de Arraial do Cabo, revelou-se que em 2002 as ZCVSL, ZCVS-C3 e ZCVS-N (FIGURA 3) não existiam. As respectivas zonas (ZCVS-L, ZCVS-C3 e ZCVS-N) formavam duas ZPVS: a E e K.

A Figura 4 ilustra a área da APA de Massambaba localizada no município de Arraial do Cabo adaptada do Plano de Manejo da APA de 2009 (RIO DE JANEIRO, 2009) com as suas respectivas zonas, com a sobreposição das informações das zonas contidas no Plano de Manejo de 2002. A imagem de fundo é o Zoneamento Ambiental de 2009, enquanto a sobreposição feita em SIG, com aspecto sombreado, são as informações contidas no Plano de Manejo de 2002.

Observa-se na ilustração que a atuais zonas (ZPVS-B, ZCVS -N, ZPVS-D, ZCVS-C3 e ZCVS-I) correspondiam a uma única ZPVS (E) em 2002. Portanto houve uma fragmentação dessa ZPVS-E em diferentes zonas, com diferentes graus de restrição de uso e cobertura da terra.

Segundo o Plano de Manejo de 2002 as ZPVSs da APA de Massambaba não admitiam o parcelamento e edificação do solo, exceto em caso de obras indispensáveis a recuperação e fiscalização da APA. Já na versão de 2009 as ZPVSs permitem usos recreativos e comerciais e a transformação de alguns usos para fins turísticos, temáticos, ecológicos e hoteleiros das construções existentes, desde que atendidas determinações contidas no Plano de Manejo da APA (INEA, 2002; RIO DE JANEIRO, 2009). 


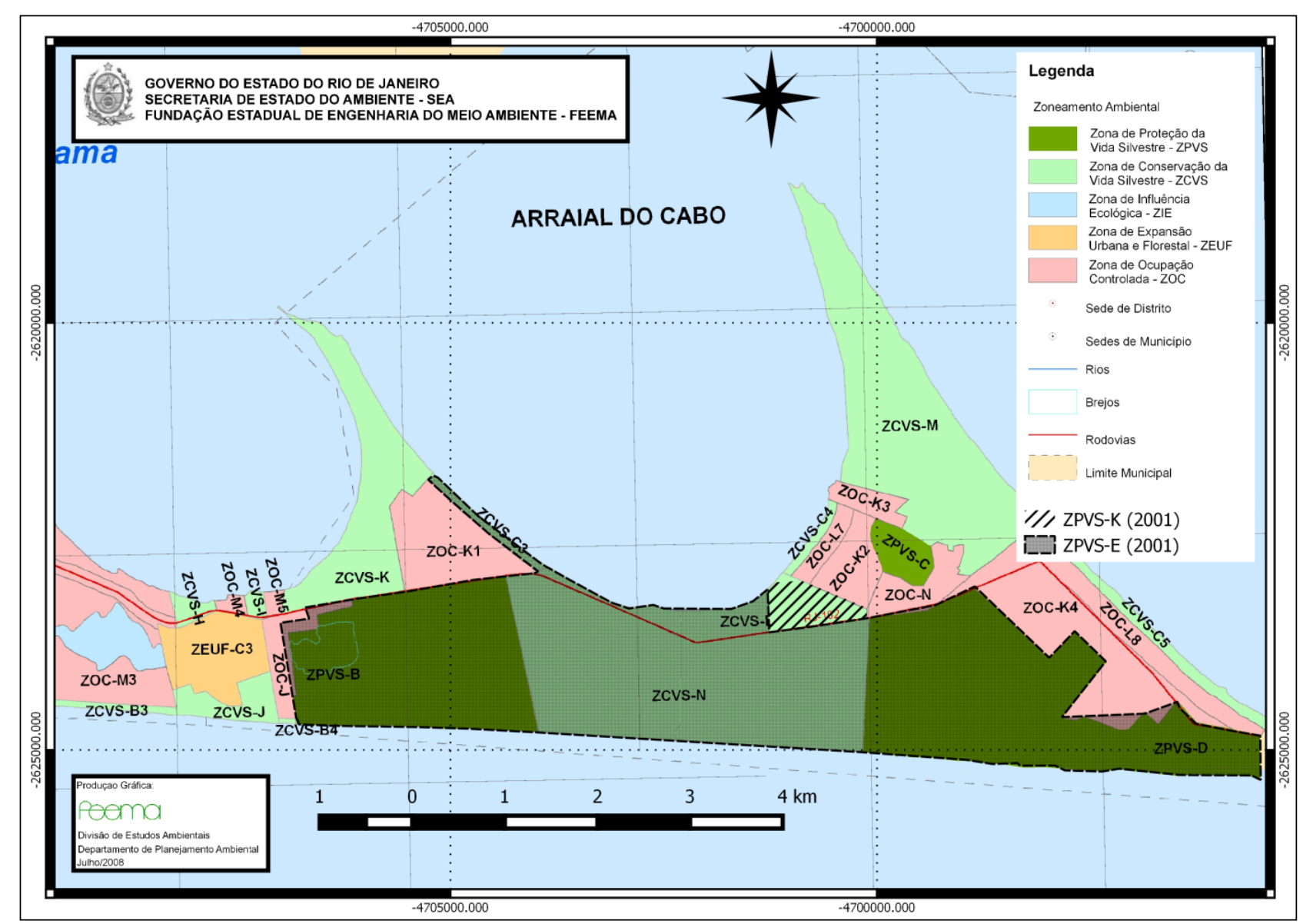

Figura 4: Ilustração da Área da APA de Massambaba no município de Arraial do Cabo, com sobreposição de informações dos Planos de Manejo de 2002 e 2009.

Fonte: INEA (2002); RIO DE JANEIRO (2009), adaptado pelos autores em 2015.

Em relação às ZCVSs no ano de 2002 o Plano de Manejo não permitia o parcelamento do solo exceto: (a) para residências unifamiliares já existentes, legalizadas, com no máximo 50\% de área construída do lote e onde a taxa de ocupação da região não ultrapasse 20\%; (b) para empreendimentos turísticos já existentes e legalizados, com as mesmas condições de ocupação das residências unifamiliares; e (c) para transformações de alguns usos atuais para fins turísticoecológicos e de educação ambiental, desde que atendidas as determinações do plano e sujeitas a aprovação do conselho gestor. No ano de 2009 as restrições de uso e cobertura da terra das ZCVSs proibiam edificações de qualquer tipo, exceto aquelas relativas à rede hoteleira (INEA, 2002; RIO DE JANEIRO, 2009).

Assim percebe-se:

(a) existe uma permissividade que fragiliza o objetivo de conservar áreas consideradas frágeis e de importância ambiental, histórica, geológica e cultural. A ZPVS que possuía fins de preservação passa de uma zona restritiva que só permitia obras voltadas a atividade fim da unidade, para uma zona com usos diretos, dentre eles os turísticos e hoteleiros;

(b) a ZCVS, que era uma zona voltada a preservação de áreas com qualidade ambiental e a recuperação de áreas degradadas, passa a ser uma zona voltada a preservação ou a hotelaria; 
(c) a ZCVS permitia o uso direto do seu espaço e recursos nos casos de moradias unifamiliares e empreendimentos turísticos e hoteleiros já existentes, legalizados e com sustentabilidade. Com a revisão do plano os residentes antes legais e com direito adquirido, passam a ser considerados invasores e irregulares, além da área da zona passar a permitir irrestritamente empreendimentos hoteleiros.

Assim, indaga-se se as alterações do Zoneamento Ambiental da APA de Massambaba favoreceram a futura instalação do Eco Resort em processo de licenciamento, ou se o empreendimento se favoreceu dessas alterações para a sua instalação. Com base nessas informações acredita-se que a mudança no Zoneamento Ambiental da APA de Massambaba de 2002 para 2009, tenha sido feita para favorecer o empreendimento do Eco resort, pois as antigas restrições não permitiriam a instalação de uma rede hoteleira na localidade.

A principal razão para se acreditar nisso se deve:

(i) a fragmentação da ZPVS-E em duas ZCVS e duas ZPVS, que tornou o Brejo do Espinho em uma categoria de restrição mais permissiva mesmo sendo uma área extremamente frágil, APP, de importância ambiental, histórica, geológica e cultural. O Brejo do Espinho também é considerado impróprio para urbanização segundo Plano Diretor de Arraial do Cabo e é tombado como patrimônio histórico em função de nele encontrarem-se catalogados quatro sambaquis: Sambaqui Brejo do Mato II, Sambaqui Brejo do Mato I, Sambaqui Dunas da Praia Seca e Sambaqui Salinas Sal Neve (ARRAIAL DO CABO, 2006; 2007).

(ii) o nível de restrição da ZPVS e ZCVS se tornaram mais permissivos, principalmente em relação à instalação de uma rede hoteleira, que antes era vedada. As alterações nas restrições também criminalizam os moradores locais legalizados, que agora irregulares devem ser removidos da área e reassentados em outro lugar.

Atenta-se que órgão ambiental estadual competente parece ter desconsiderado o fato da área escolhida para instalação do Eco Resort estar contida no Parque Estadual da Costa do Sol, UC de sua própria gestão e fiscalização, e por isso, é vedado o uso direto dos recursos naturais.

\section{CONFLITOS DE USO E COBERTURA DA TERRA NA APA DE MASSAMBABA}

A histórica especulação imobiliária em Arraial do Cabo, mediada pela implantação de grandes empreendimentos e posteriormente pelo turismo, ocasionou a segregação residencial de grande contingente da sua população, afetando principalmente a mais vulnerável economicamente.

Com isso, os mais vulneráveis passaram a ocupar as áreas mais afastadas do centro da cidade, destituídas de infraestrutura urbana adequada, como nos termos definidos pelo Plano Diretor do município. Ainda, as áreas ocupadas por essas populações, no geral, são ecologicamente frágeis, 
de antigas salinas, de risco ambiental e de preservação permanente, da APA de Massambaba, além de consideradas patrimônio histórico e cultural.

Segundo Acselrad et al., (2009) quando há sobreposição de áreas frágeis, degradadas ou de risco ambiental, com uma população socialmente e economicamente vulnerável, em uma mesma temporalidade e espacialidade tem-se um processo de injustiça ambiental. Então, pelo cenário posto, conclui-se que na área de estudo podem existir casos de injustiça ambiental.

O conceito de injustiça ambiental afirma que certos grupos vulneráveis economicamente e socialmente estão mais expostos a riscos ambientais e esses grupos são aqueles que suportam a maior parte dos efeitos negativos à saúde e ao ambiente. Esse conceito enfatiza a distribuição desigual do risco ambiental entre os pobres e as minorias étnicas, em relação ao conjunto da sociedade como um todo (ACSELRAD et al., 2009).

A APA de Massambaba é um dos poucos remanescentes de restinga protegidos do estado do Rio de Janeiro. No ano de 2016, a porção da APA em Arraial do Cabo encontra-se sitiada por moradias de população economicamente vulnerável, salineiras e a possibilidade da instalação do Eco Resort.

Nos últimos anos diversas ações judiciais promoveram a remoção de construções residenciais decorrentes da ocupação desordenada nas diferentes zonas da APA com intuito de preservá-la. Assim, a sociedade civil, por meio das manifestações em meios de comunicação, protesta sobre a instalação de Eco Resort com o tema "Barracos não, mas Resort pode?" (BLOCO DO CLOVIS, 2014), questionando o fato de casas não poderem ocupar o espaço da APA, enquanto o Eco Resort teria o direito a essa ocupação.

Esses grupos defendem seu ponto de vista por meio da apelação ao direito a moradia, o de utilidade pública da área e contradizem o direito do empreendimento Eco Resort ao uso do espaço por esse ter fins privados e lucros voltados para seus investidores.

No discurso dos que defendem o Eco Resort, está a ineficiência do estado em impedir a "favelização" da área e sua degradação ambiental. Assim, criminaliza-se a "pobreza" pela ocupação desordenada daquele espaço e objetiva-se retirá-la de uma área de beleza cênica, valor imobiliário e turístico. A ocupação desordenada por "barracos", segundo os defensores do empreendimento, nesse caso, poderia ser substituída pela ocupação ordenada e pouco impactante do Eco Resort (ALENCAR, 2012).

Para Marcuse (2004), a remoção de pessoas vulneráveis sócio economicamente para áreas ermas, caracteriza o processo de gentrificação. No caso específico da remoção de pessoas na APA de Massambaba, a gentrificação agrava a injustiça ambiental, pois essas pessoas estão sendo assentadas em áreas de antigas salinas, que foram consideradas impróprias para edificações por não possuírem infraestrutura básica de saneamento, transporte, comércio e saúde. 
O problema desse conflito é que se criou uma fragilidade legal em função das mudanças observadas no Plano de Manejo e em seu Zoneamento Ambiental que podem prejudicar ainda mais a gestão e a conservação da APA, além de dificultar a estabilização dos conflitos observados.

Nesse caso, a delimitação da ZCVS-N em meio a duas ZPVS (ZPVS-B e ZPVS-D) e as alterações das restrições de uso e cobertura da terra dessas zonas para aquelas mais permissivas direcionam uma ocupação da área e o uso dos recursos naturais de forma direta, o que contraria as orientações da Resolução CONAMA n. 10 de 1988, que dispõe sobre a delimitação das Zonas de Vida Silvestre de APAs, ainda não revogada nessa época.

Além disso, essas alterações também contradizem as orientações do Roteiro Metodológico para Gestão de APAs do IBAMA em relação à elaboração do Zoneamento Ambiental e ignoram a existência do Parque Estadual da Costa do Sol e de todos os regulamentos legais vistos na discussão desse trabalho que vedam a ocupação da área de estudo.

Assim, fica a pergunta: como estabilizar esse conflito entre a conservação da APA e seu patrimônio ecológico, cultural, geológico e histórico, o direito a moradia e a instalação de um empreendimento hoteleiro? se existe uma lacuna legal nos instrumentos de gestão da unidade que privilegia interesses e atores específicos, além da falta de comprometimento do poder público para com a gestão e a fiscalização da área?

\section{CONSIDERAÇÕES FINAIS}

Por meio deste trabalho evidenciou-se que houve alterações no Plano de Manejo e Zoneamento Ambiental da APA de Massambaba, com intuito de favorecer atores específicos e interesses particulares. Com isso, criou-se uma fragilidade legal que prejudica a gestão da APA e a concretização de seus objetivos de conservação do ambiente e uso dos recursos naturais com sustentabilidade.

Com a instalação do Eco Resort existe a possibilidade de mais pessoas serem atraídas para região do entorno da APA, o que pode promover uma maior pressão sob a área da UC e de outras áreas protegidas. Teme-se que esse processo poderá ocorrer com o incremento da atração de pessoas socioeconomicamente vulneráveis em busca de empregos, com um novo quadro de segregação residencial da classe econômica mais baixa da região.

A justificativa dessa análise se pauta no fato dos futuros empregos gerados pelo Eco Resort podem não ser suficientes e nem ofertar salários dignos para atender a demanda crescente de uma população na área.

Alerta-se que as ZCVS e ZPVS da APA de Massambaba em Arraial do Cabo que sofreram alterações para beneficiar o Eco resort também fazem parte do Parque Estadual da Costa do Sol. 
Dessa forma, todas as áreas particulares devem ser desapropriadas conforme a legislação pertinente, sejam elas barracos ou Ecoresort. Assim, o empreendimento em questão não deveria ser licenciado e os residentes na área da UC devem ou ser indenizados pelo processo de desapropriação, ou removidos a outras residências em outras áreas, atentando para não promoção de injustiça ambiental com os removidos.

\section{REFERÊNCIAS}

ACSELRAD, H.; MELLO, C.C.A.; BEZERRA, G.N. O que é justiça ambiental? Rio de Janeiro Garamond, 2009. 160 p.

ALENCAR, E. MP questiona impacto de Eco Resort em Arraial do Cabo. Jornal o Globo, Edicão on line, 3 dez de 2012. Disponível em: http://oglobo.globo.com/rio/mp-questiona-impactosde-eco-resort-em-arraial-do-cabo-6918809. Acesso em: 28 de fevereiro de 2016.

ALVAREZ, A. D.; DEVELEY, P., F.; VECCHI, M.B.;ALVES, M. A. S. Plano de ação nacional para a conservação do formigueiro-do-litoral:(Formicivora littoralis). Brasília: Instituto Chico Mendes de Conservação da Biodiversidade, 2010.

ARAÚJO, D.D; SÁ, C.F.C; PEREIRA, J.F.; GARCIA D. S.; FERREIRA, M. V.; PAIXÃO, R.J.; SCHNEIDER, S. M.; KRUEL, V. F. Área de Proteção Ambiental de Massambaba, Rio de Janeiro: Caracterização fitofisionômica e florística. Revista Rodriguésia, v. 60, n 1. p. 67 -96, 2009.

ARRAIAL DO CABO. Um paraíso chamado Arraial do Cabo. (s.d). Disponível em: <http://www.arraial.rj.gov.br/prefeitura/?local=nossa_cidade\&submenu=ativo>. Acesso em: 03 de dezembro de 2015.

ARRAIAL DO CABO. Lei Municipal no 1.512 de 30 de março de 2007. Dispõe sobre o uso e ocupação do solo do município de Arraial do Cabo. Arraial do Cabo, 2007.

ARRAIAL DO CABO. Lei Municipal no 1.496 de 30 de outubro de 2006. Dispõe sobre o Plano Diretor Municipal. Arraial do Cabo, 2006.

BERANGER, A. Dados históricos de Cabo Frio: Cabo Frio, 500 anos de História 1503 -2003. 3 ed. Cabo Frio. Câmara Municipal de Cabo Frio, 2003. 103 p.

BLOCO DO CLOVIS. Barracos não, mas Resort pode!. Blog de acesso restrito. Acesso em 8 de novembro de 2014.

BRASIL. Lei Federal n ${ }^{\circ}$ 12.651, de 25 de maio de 2012. Dispõe sobre a proteção da vegetação nativa; altera as Leis $n^{\circ} 6.938$ de 31 de agosto de 1981[...] Brasília: DOU de 28/5/2012.

BRASIL. CONAMA - Conselho Nacional de Meio Ambiente. Resolução CONAMA no 428 de 17 de dezembro de 2010. Dispõe, no âmbito do licenciamento ambiental sobre a autorização do órgão responsável pela administração[...]. Brasília: DOU nº 242 de 20/12/2010.

BRASIL. Decreto Federal 4.887 de 20 de novembro de 2003. Regulamenta o procedimento para identificação, reconhecimento, delimitação, demarcação e titulação das terras ocupadas por 
remanescentes das comunidades dos quilombos de que trata o art. 68 do Ato das Disposições Constitucionais Transitórias. Brasília: DOU n ${ }^{\circ} 227$ de 21/11/2003.

BRASIL. CONAMA - Conselho Nacional de Meio Ambiente. Resolução CONAMA n ${ }^{\circ}$ 303, de 20 de março de 2002. Dispõe sobre parâmetros, definições e limites de Áreas de Preservação Permanente. Brasília: DOU de 13/05/2002.

BRASIL, Ministério do Meio Ambiente. Lei Federal n. 9.985, de 18 de julho de 2000. Regulamenta o Art. $225^{\circ}$, par. $1^{\circ}$, incisos I, II, III E VII da Constituição Federal, institui o Sistema Nacional de Unidades de Conservação da Natureza e dá outras providências. DOU de 19/7/2000.

BRASIL. Decreto Federal s/n de 3 de janeiro de 1997. Dispõe sobre a criação da Reserva Extrativista Marinha do Arraial do Cabo, no Município de Arraial do Cabo, Estado do Rio de Janeiro, e dá outras providências. Brasília: DOU de 6/1/1997.

BRASIL. Decreto Federal 1.775 de 8 de janeiro de 1996. Dispõe sobre o procedimento administrativo de demarcação das terras indígenas e dá outras providências. Brasília: DOU de 09/01/1996.

BRASIL. CONAMA - Conselho Nacional do Meio Ambiente. Resolução no 10 de 14 de dezembro de 1988. Dispõe sobre Áreas de Proteção Ambiental. DOU de 11/08/1989.

BRASIL. Lei Federal $\mathbf{n}^{\circ} \mathbf{6 . 9 0 2}$, de 27 de abril de 1981. Dispõe sobre a criação de Estações Ecológicas, áreas de Proteção Ambiental e dá outras providências. DOU de 27/04/1981.

DAGNINO, R., S.; JUNIOR, S. C. Risco ambiental: conceitos e aplicações. Climatologia e Estudos da Paisagem, Rio Claro, v. 2, n. 2, p.50, julho/dezembro de 2007.

GASPAR, M. D. Sambaqui: Arqueologia do litoral brasileiro. 2 ed. Rio de Janeiro: Jorge Zahar, 2004. $92 \mathrm{p}$.

GERÊNCIA DE UNIDADES DE CONSERVAÇÃO DE PROTEÇÃO INTEGRAL. Parque da Costa do Sol. Disponível em: <http://geproinearj.blogspot.com.br/p/parques-estaduais-do-rio-dejaneiro.html>. Acesso em: 04 de dezembro de 2014.

IBAMA - Instituto Brasileiro do Meio Ambiente e dos Recursos Naturais. Roteiro Metodológico para Gestão de Área de Preservação Ambiental. Rio de Janeiro, IBAMA, 2001. 252 p.

IBGE - Instituto Brasileiro de Geografia e Estatística. População residente por sexo e situação de domicílio, Arraial do Cabo, 1970-2010. 2014. Disponível em:

<http://www.sidra.ibge.gov.br/bda/tabela/listabl.asp?z=cd\&o=2\&i=P\&c=202>. Acesso em: 04 de dezembro 2014.

INEA - Instituto Estadual do Ambiente. Estudo de Impacto Ambiental (EIA) Eco Resort Massambaba. 2012. Disponível em: <http://rap.gov.br/?p=210>. Acesso em: 04 de dezembro de 2014.

INEA - Instituto Estadual de Ambiente. Plano de Manejo da Área de Proteção Ambiental de Massambaba - APA de Massambaba. Rio de Janeiro, FEEMA, 2002, 79 p.

MARCUSE, P. Enclaves, sim; guetos, não: a segregação e o estado. In: NERU, C. Espaço e Debates, São Paulo: v. 24, n. 45. p. 24 - 33. 2004. 
MELLO, L. V.; SALES, T.B.; SOUZA, G.L.; BRANT, F. F.; MANICACCI, M. Ampliação do Porto do Forno na Reserva Extrativista Marinha em Arraial do Cabo - RJ. Boletim do Observatório Ambiental Alberto Ribeiro Lamego. Campos dos Goytacazes, v.3, n.2, p. 163-186, 2009.

PEREIRA, W. L. C. M. História e Região: Inovação e industrialização na economia salineira Fluminense. Revista de História Regional, n.15, v.2, p. 184-210, 2010.

PEREIRA, W. L. C. M. Cabo das tormentas e vagas da modernidade: uma história da Companhia Nacional de Álcalis e de seus trabalhadores. 2009. Tese (Doutorado em História) Niterói, Rio de Janeiro: Universidade Federal Fluminense.

RIBEIRO, C.; GRANATO, M. A patrimonialização do legado da CIA. de Álcalis.(s.d.) Disponível em: <http://portal.iphan.gov.br/portal/baixaFcdAnexo.do?id=2979>. Acesso em: 05 de Dezembro de 2014.

RIO DE JANEIRO. Decreto Estadual $\mathbf{n}^{\circ} 42.929$ de 18 de abril de 2011. Cria o Parque Estadual da Costa do Sol e dá outras providências. Rio de Janeiro: DO de 19/04/2011.

RIO DE JANEIRO. Decreto Estadual $n^{0} 41.820$ de 16 de abril de 2009. Aprova o Plano de Manejo da Área de Proteção Ambiental de Massambaba [...]. Rio de Janeiro: DO de 16/04/2009.

RIO DE JANEIRO. SEA - Secretaria do Estado de Ambiente. Decreto Estadual no 9.529-C, de 15 de dezembro de 1986. Cria a Área de Proteção Ambiental na Lagoa de Araruama e Praia de Massambaba (APA de Massambaba) e dá outras providências. Rio de Janeiro: DO de 15/11/1986.

SAVI, D. C. 500 anos de ocupação portuguesa. Evolução histórica da enseada dos anjos, Arraial do Cabo, Rio de Janeiro, Brasil. In: II CONGRESSO SOBRE PLANEJAMENTO E GESTÃO DAS ZONAS COSTEIRAS DOS PAÍSES DE EXPRESSÃO PORTUGUESA, 2003, Recife. Anais... Pernambuco: UECE, 2003.

TERRA, A. D. G. Uma janela para o mar: Ocupação irregular na localidade de Monte Alto, na Restinga de Massambaba, Em Arraial do Cabo - RJ. . In: XXI ENCONTRO NACIONAL DO CONPEDI, 2012, Uberlândia. Anais... Minas Gerais: UFU, 2012. p. 10437-10467.

TERRA, A. D. G. O sal da terra:ocupação irregular em área de expansão turística, o caso da localidade de poças, na restinga de Massambaba, em Arraial do Cabo - RJ. In: XXI ENCONTRO NACIONAL DO CONPEDI, 2012, Uberlândia. Anais... Minas Gerais: UFU, 2012. p. 14266$14285 b$.

Trabalho enviado em 29/02/2016

Trabalho aceito em 17/01/2017 